\title{
Improving the Control Strategy of a Standalone PV Pumping System by Fuzzy Logic Technique
}

\author{
Houssem CHAOUALI ${ }^{(*)}$, Hichem OTHMANI, Dhafer MEZGHANI, Abdelkader MAMI \\ UR-LAPER, Faculty of Sciences of Tunis, \\ University of Tunis El Manar \\ 2092 Tunis, Tunisia
}

\begin{abstract}
This work aims to develop an accurate model of an existing Photovoltaic Pumping System (PvPS) which is composed of an Ebara Pra-0.50T Asynchronous Moto-Pump (AMP) fed by Kaneka GSA-60 photovoltaic panels via a Moeller DV-51 speed drive. The developed model is then used to compare the performance of the system with its original control strategy based on classical indirect vector control strategy using PI speed controller and the proposed new control strategy based on Fuzzy Logic control technique for speed control and MPPT system. The obtained results of comparative simulations, induced in different dramatic variation of working conditions, show that the developed control strategy brought major enhancements in system performance.
\end{abstract}

Keywords-Photovoltaic Pumping System; Asynchronous Moto-Pump; PI Speed Controller; Fuzzy Logic Control Technique; MPPT Tracking System; Simulation

\section{INTRODUCTION}

Air pollution problems and its disastrous consequences mainly caused by increasing consumption of conventional energy sources such as gas, oil and coal, has encouraged scientific society towards developing environmentally friendly energy sources which are mainly extracted from renewable energy sources such as the sun, water, wind... etc.

Among these new energy sources, and thanks to its continuous technological progress and manufacturing cost reduction, Photovoltaic (PV) energy presents one of best choices from different existing renewable energy sources.

PV technologies are widely used for numerous and various types of applications [1,2]. For some countries, especially where agriculture is an important economic engine such as Thailand [3], pumping water using PV generator (PVG) is a practical solution for rural development where water demand for irrigation and domestic use, is increasing. PV pumping importance is related to the fact that these rural areas are generally without electricity supply sources. [4]

In these cases, different types of PV pumping systems have rapidly replaced traditional pumps such as diesel and gasoline pumps especially that these developed new technologies help to avoid the need for maintenance personnel and fuel supply problems [5]. Despite these different advantages, the generated PV power is strongly dependent on weather conditions especially solar irradiation which contributes constantly in rapid variation of $\mathrm{I}-\mathrm{V}$ and $\mathrm{P}-\mathrm{V}$ characteristics of the PVGs [6].
This fact might explain the totally degraded performance that was found in early stage of PV pumping application in comparison with same pumping systems once supplied with a constant voltage source. Trying to fix this problem, later studies suggested that using a DC/DC converter as an adaptation between the load and the source guaranties major improvements in the used motor characteristics as well as the generated power from the PVG [7].

Therefore, researches have been focusing on developing different algorithms and techniques to be used in computing the optimal duty cycle of the DC-DC converter to ensure the better tracking of the Maximum Power Point (MPP) continuously in spite of irradiation variations [8].

In another hand, it is known that different types of disturbances, intern or extern, heavily influence the dynamic performance of several industrial systems such as power systems [9]. In this context, different types of controllers have been introduced over the years. But unlike conventional controllers, Fuzzy Logic (FL) controllers have proved better efficiency in different industrial processes thanks to its robustness. Thus, this reality made us think to apply an upgrade, by using the FL technique, of the existing control strategy of a Photovoltaic pumping system. [10]

This paper gives in a first place a general overview of the system where its different blocks are presented and modeled separately:

- The model of the PV generator which is composed by Kaneka GSA-60 PV panels.

- The model of the 3 phased digital speed drive inverter which is a Moeller DV51 type.

- The model of the 3 phased asynchronous machine and the trained centrifugal pump which both form the studied moto-pump type Ebara Pra-0.50T.

Then, the next section presents is reserved for presenting the actual control strategy and the upgraded one. In this part, we give a general presentation of the Fuzzy Logic technique and how we deployed different FLCs in the system in order to improve its control strategy.

In the last section, we present several results comparing the behaviour of the pumping system with and without the developed FL control strategy and the major proved enhancements in performance. 


\section{GENERAL OVERVIEW OF THE STUDIED SYSTEM}

\section{A. Description of the studied system}

The system we are working on can be simply presented, as shown in Fig. 1, by a 3 phased Asynchronous Moto-Pump (AMP) fed by a DC source, in our case a GPV, via a 3 phased DC-AC inverter speed drive which includes an integrated speed control system.

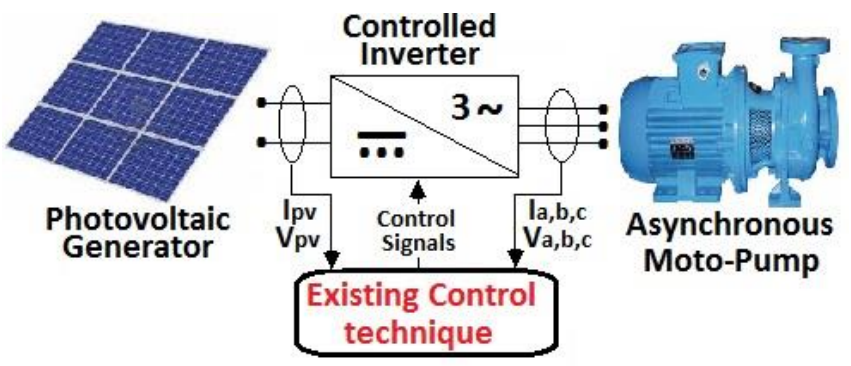

Fig. 1. The block diagram of the studied system

In the next subsections, we are giving a general presentation of every part of this system along with its different features and the different equations used to develop the simulation model.

\section{1) Kaneka GSA-60 Photovoltaic Generator (GPV)}

The GPV that our research lab disposes is composed of 5 Kaneka GSA-60 panels, mounted in series, as shown in Fig.2. and situated on the roof of physics department of the Faculty of Sciences of Tunis (El Manar - Tunisisa).

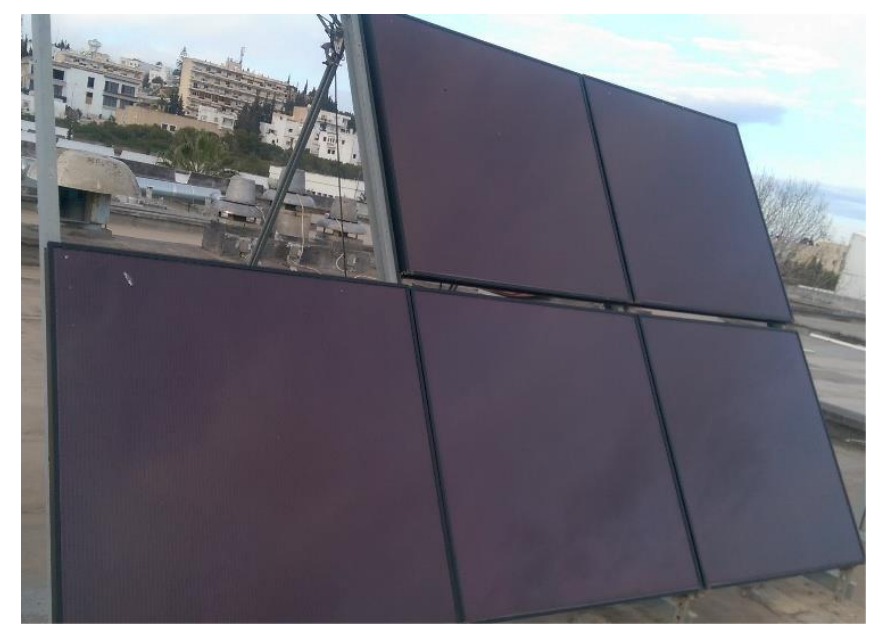

Fig. 2. Kaneka GSA-60 photovoltaic generator

The used model in simulation is developed according to the features given in Table1 of a single PV module type Kaneka GSA-60.

TABLE I. KANEKa GSA-60 SingLe Module Features

\begin{tabular}{|l|l|}
\hline Parameter & Value \\
\hline Pmpp & $60 \mathrm{~W}$ \\
\hline Vmpp & $67 \mathrm{~V}$ \\
\hline Impp & $0.9 \mathrm{~A}$ \\
\hline Voc & $92 \mathrm{~V}$ \\
\hline Isc & $1.19 \mathrm{~A}$ \\
\hline
\end{tabular}

Figure 3presents both I-V and P-V characteristic curves of 1 single module, and Figure 4 presents the same curves of the GPV. These curves are obtained by maintaining the temperature at $25^{\circ} \mathrm{C}$ and varying the solar irradiance in order to show its influence on the generated current.

\section{2) The Moeller 3 phased Inverter}

The fact that, the GPV is a DC generator and the Asynchronous machine presents a 3 phased AC load, which requires the use of a 3 phased inverter.

In another hand, to ensure the speed control of the machine, consecutively the pumping performance, we use a 3 phased speed drive.
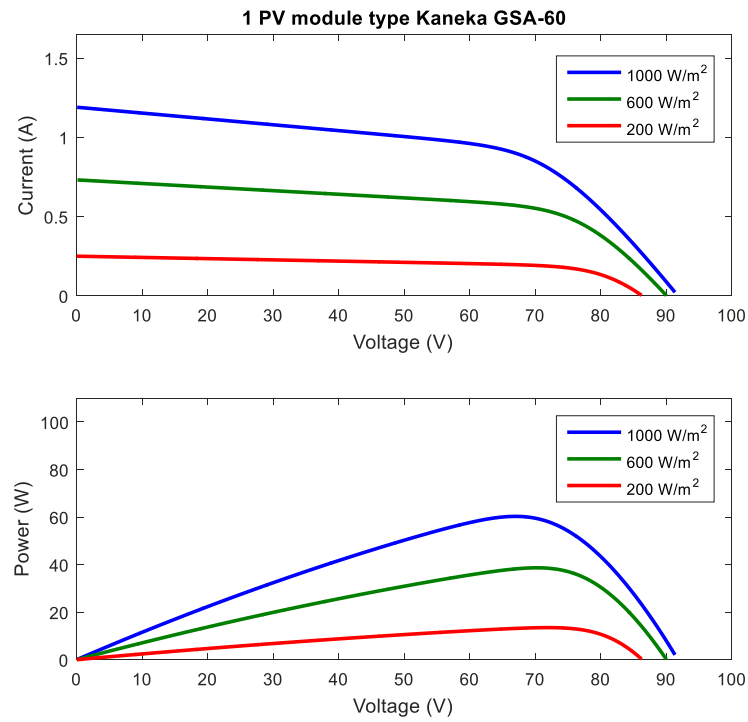

Fig. 3. The influence of solar irradiation variation on I-V and P-V characteristics of a single Kaneka GSA-60 module
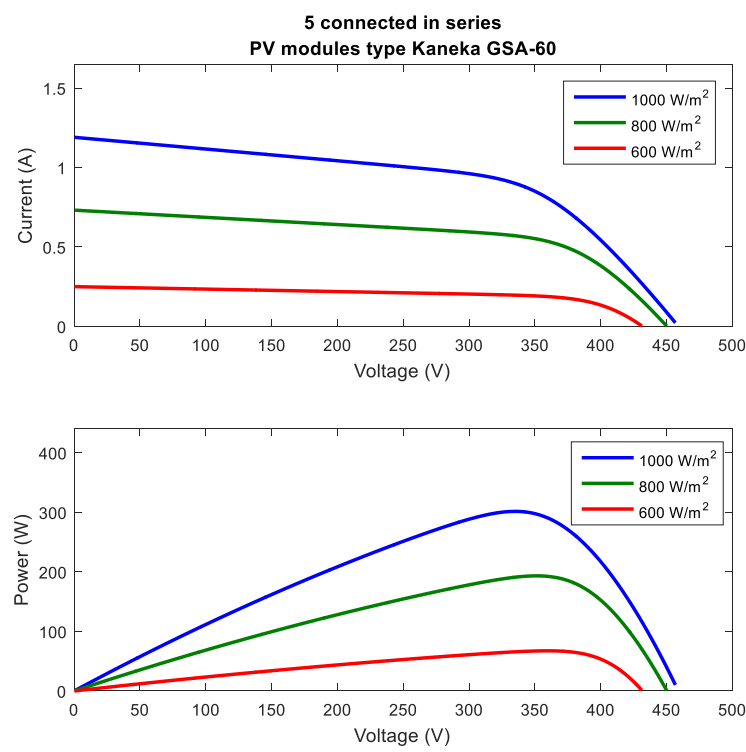

Fig. 4. The influence of solar irradiation variation on I-V and P-V characteristics of 5 Kaneka GSA-60 PV modules connected in series 
This speed drive, shown in Figure 5. is a Moeller type DV51-2.2 Kw. His main features are presented in Table 2.

TABLE II. MAIN FEATURES OF THE USED MOELLER INVERTER

\begin{tabular}{|l|l|}
\hline Parameter & Value \\
\hline Max. Power & $2.2 \mathrm{~kW}$ \\
\hline Input Voltage & $\mathrm{AC}: 230 \mathrm{~V} / \mathrm{DC}: 400 \mathrm{~V}$ \\
\hline Output Voltage & $230 \mathrm{~V} / 400 \mathrm{~V}$ \\
\hline Control technique & Vector Control with PI speed regulation \\
\hline
\end{tabular}

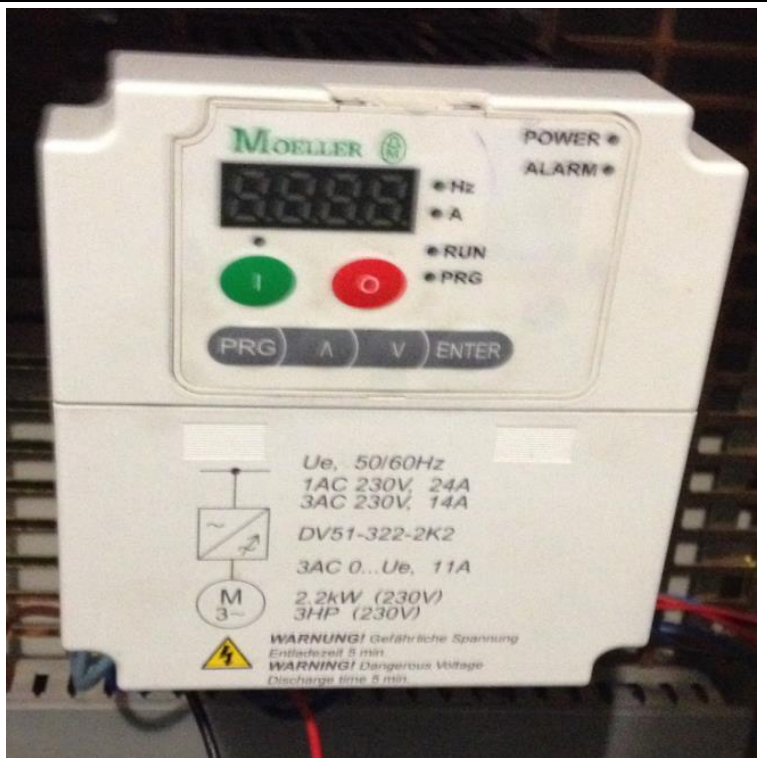

Fig. 5. The 3 Moeller DV51 Inverter

\section{3) The Asynchronous Moto-Pump (AMP)}

The Asynchronous Moto-Pump, shown in Figure 6. is composed of an electrical 3 phased asynchronous motor driving a centrifugal pump.

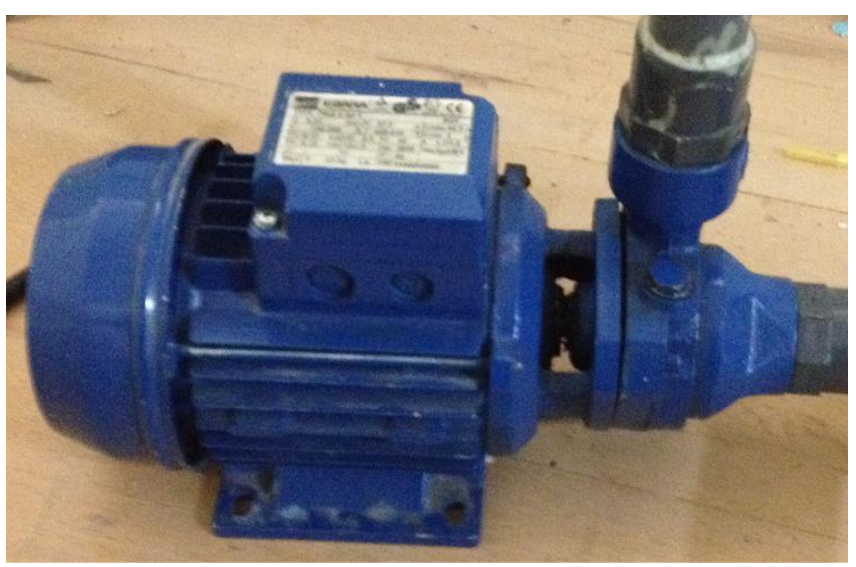

Fig. 6. 3 phased AMP type Ebara-PRA50

The studied AMP is an EBARA type where its reference is PRA50. Its different parameters given by the constructor in the Data Plate are presented by Table 3.
TABLE III. EBARA PRA-0.50T MAIN FEATURES

\begin{tabular}{|l|l|}
\hline Parameter & Value \\
\hline Power & $0.37 \mathrm{Kw}$ \\
\hline Voltage & $3 \sim 240 \mathrm{~V}$ \\
\hline Nominal Current & $1.8 \mathrm{~A}$ \\
\hline Frequency & $50 \mathrm{~Hz}$ \\
\hline P & 2 \\
\hline Cos $\rho$ & 0.8 \\
\hline Maximum Speed & $2850 \mathrm{rpm} \approx 300 \mathrm{rad} / \mathrm{s}$ \\
\hline Maximum Flow rate & $45 \mathrm{~L} / \mathrm{mn}$ \\
\hline
\end{tabular}

B. Modeling the existing system

\section{1) Model of the GPV}

In this part, we are presenting the general modeling equations of the GPV and showing the obtained different characteristic curves of the developed model, depending on solar irradiation variation.

Based on the conventional equivalent electrical circuit given in numerous references, we developed the model of our Kaneka generator using (1), (2), (3) and (4). [11,12]

$$
I_{p v}=I_{p h}-I_{D}-I_{S h}
$$

With:

$$
\begin{aligned}
I_{p h} & =I_{c c} \frac{E}{E_{r}}+k_{i s c}\left(T-T_{r}\right) \frac{E}{E_{r}} \\
I_{D} & =I_{s}\left[\exp \left(\frac{V_{p v}}{V_{T}}\right)-1\right] \\
I_{S h} & =\frac{V_{p v}+R_{s} I_{p v}}{R_{s h}}
\end{aligned}
$$

\section{2) Model of the 3 phased inverter}

Figure 7 presents the equivalent electrical scheme of the power circuit, responsible for the commutation, which we used to develop the simulation model. As shown in the figure and mentioned in numerous references such as [13,14], a 3 phased inverter is generally composed of $3 \mathrm{arms}$, each one is composed of 2 electronic switches, in this case we used a MOSFET transistor and a parallel diode for each switch.

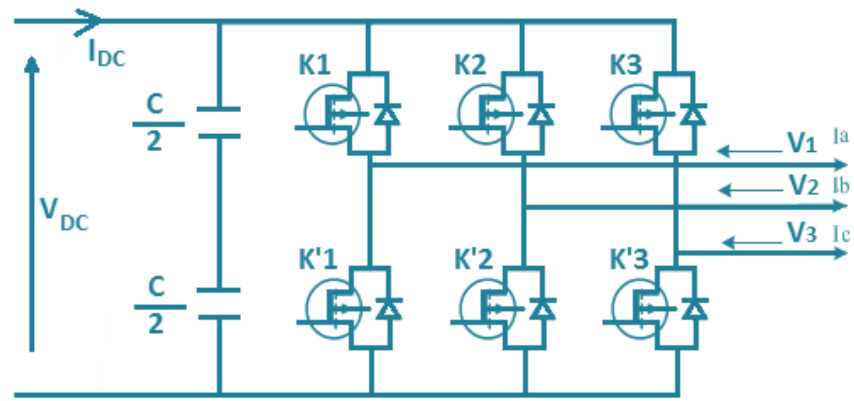

Fig. 7. General equivalent circuit of the $3 \sim$ Inverter 
Based on this electrical scheme, the different voltages can be expressed by (5) and the relation between the input and the 3 output currents is given by (6). [15]

$$
\begin{aligned}
& {\left[\begin{array}{l}
V_{1} \\
V_{2} \\
V_{3}
\end{array}\right]=\frac{V_{D C}}{3}\left[\begin{array}{ccc}
2 & -1 & -1 \\
-1 & 2 & -1 \\
-1 & -1 & 2
\end{array}\right]\left[\begin{array}{l}
K_{1} \\
K_{2} \\
K_{3}
\end{array}\right]} \\
& I_{D C}=K_{1} I_{a}+K_{2} I_{b}+K_{3} I_{c}
\end{aligned}
$$

3) Model of the AMP

The next two subsections present each part of the AMP independently and modelling equations are presented.

\section{a) Model of the Asynchronous Motor}

Different AM voltages at the stator and the rotor windings of the asynchronous machine can be modelled by equations (10) and (11) as shown in [16]:

$$
\begin{aligned}
& {\left[V_{s i}\right]=\left[R_{s}\right] \cdot\left[I_{s i}\right]+\frac{d\left[\phi_{s i}\right]}{d t}} \\
& {\left[V_{r i}\right]=\left[R_{r}\right] \cdot\left[I_{r i}\right]+\frac{d\left[\phi_{r i}\right]}{d t}}
\end{aligned}
$$

\section{Where}

$\mathrm{s}$ refers to stator, $\mathrm{r}$ refers to rotor and $\mathrm{i}$ refers to the winding.

Also, we can model the flux in both stator and rotor by the system of equations (9).

$$
\left\{\begin{array}{l}
{\left[\phi_{s}\right]=\left[L_{s s}\right] \cdot\left[I_{s}\right]+\left[L_{s r}\right] \cdot\left[I_{r}\right]} \\
{\left[\phi_{r}\right]=\left[L_{r s}\right] \cdot\left[I_{s}\right]+\left[L_{r r}\right] \cdot\left[I_{r}\right]}
\end{array}\right.
$$

where

$\left[\mathrm{L}_{\mathrm{ss}}\right]$ is the matrix of stator inductances and given by (10)

$\left[\mathrm{L}_{\mathrm{rr}}\right]$ is the matrix of rotor inductances and given by (11)

$\left[\mathrm{L}_{\mathrm{sr}}\right]$ and $\left[\mathrm{L}_{\mathrm{rs}}\right]$ are the matrix of mutual inductances between the rotor and stator and given by (12)

$$
\begin{aligned}
& {\left[\mathrm{L}_{\mathrm{ss}}\right]=\left[\begin{array}{ccc}
l_{s} & M_{s} & M_{s} \\
M_{s} & l_{s} & M_{s} \\
M_{s} & M_{s} & l_{s}
\end{array}\right]} \\
& {\left[\mathrm{L}_{\mathrm{rr}}\right]=\left[\begin{array}{ccc}
l_{r} & M_{r} & M_{r} \\
M_{r} & l_{r} & M_{r} \\
M_{r} & M_{r} & l_{r}
\end{array}\right]}
\end{aligned}
$$

$$
\left[L_{s r}\right]=\left[L_{r s}\right]^{T}=M_{s r .} \cdot\left[\begin{array}{ccc}
\cos \left(\psi^{\prime}\right) & \cos \left(\psi^{\prime}+\frac{2 \pi}{3}\right) & \cos \left(\psi^{\prime}-\frac{2 \pi}{3}\right) \\
\cos \left(\psi^{\prime}-\frac{2 \pi}{3}\right) & \cos \left(\psi^{\prime}\right) & \cos \left(\psi^{\prime}+\frac{2 \pi}{3}\right) \\
\cos \left(\psi^{\prime}+\frac{2 \pi}{3}\right) & \cos \left(\psi^{\prime}-\frac{2 \pi}{3}\right) & \cos \left(\psi^{\prime}\right)
\end{array}\right]
$$

with

$1_{\mathrm{s}}, 1_{\mathrm{r}}$ : stator and rotor proper inductances.

$\mathrm{M}_{\mathrm{s}}, \mathrm{M}_{\mathrm{r}}$ : Stator, respectively rotor, mutual inductance between two of its windings.

$\mathrm{M}_{\mathrm{sr}}$ : maximal mutual Inductance between one winding of the stator and another one of the rotor.

the electrical position of the machine is given by (13)

$\psi^{\prime}=p \psi$

where

$\psi$ : rotor real position (mechanical angle).

$\psi^{\prime}$ : rotor electrical position.

$\mathrm{p}$ : numberof pairs of pole in the machine.

And finally, the mechanical model of the machine can be expressed like shown in equation (14):

$T_{e m}-T_{L}-f \Omega=J \frac{d \Omega}{d t}$

where

$f \quad$ : Viscous friction coefficient of the machine.

$J$ : Inertia moment of the rotating masses.

$T_{e m}$ : Electromagnetic torque.

$T_{L}$ : Load torque.

$\Omega \quad$ : Rotor speed.

b) Model of the Centrifugal Pump

The centrifugal pump have a proportional resistive torque $\left(\mathrm{C}_{\mathrm{r}}\right)$ to the square of its rotational speed $(\Omega)$. This aerodynamic relation is given by (15) as shown in [17].

$T_{L}(\Omega)=C_{2} \Omega^{2}$

where

$C_{2}$ is the torque constant of the pump.

The mechanical losses applied at the AMP shaft are presented by the set of torques $C_{f v}(\Omega)$ which is proportional to the speed.

$C_{f v}(\Omega)$ is described by (16) as shown in [18]. 
$C_{f v}=C_{1} \Omega$

where

$C_{l}$ is the coefficient of viscous friction.

To the previously presented torques, we add the acceleration torque $\frac{J d \Omega}{d t}$. So, the electromagnetic torque expression given in (14) is now described by (17).

$T_{e m}=C_{2} \Omega^{2}+C_{1} \Omega+J \frac{d \Omega}{d t}$

Where

$C_{l}$ is the same coefficient $f$.

\section{PROPOSED IMPROVEMENTS BASED ON FUZZY LOGIC CONTROL TECHNIQUE}

A. General overview on applied F.L controllers on the system

Since 1965, after being proposed by Lotfi Zadeh, Fuzzy logic technique has become very common tool in developing intelligent controllers that have replaced conventional techniques and introduced many improvements in decision making with complex systems. [19]

In this context, we tried to enhance our system by integrating FL controllers, as shown in Figure 8. by upgrading the existing speed control system with an FL controller and adding a controlled DC-DC controller where it's duty cycle is computed by an MPPT algorithm based on FL technique.

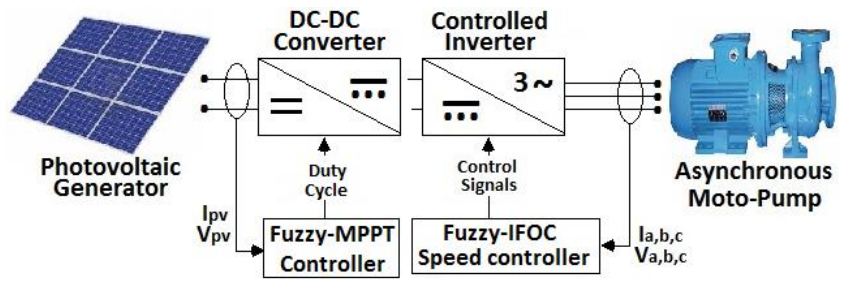

Fig. 8. Block diagram of the new control strategy

Generally, a Fuzzy Logic Controller works by applying 3 main steps on the input data in order to take the decision, the output. Figure 9 presents the working principle of an FLC and its different phases which are: The Fuzzification phase, applying predefined rules by the Inference Engine and finally the defuzzification phase. [ 20,21$]$

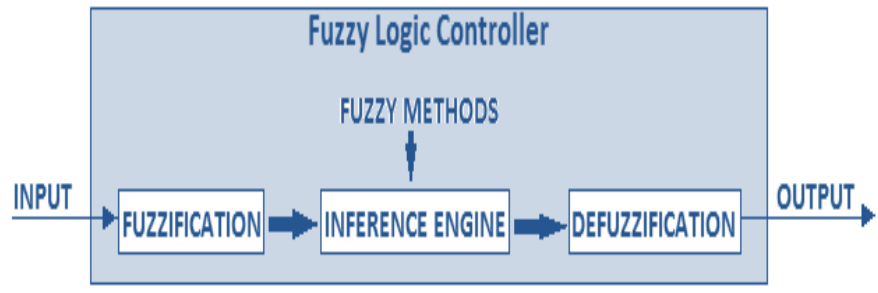

Fig. 9. F.L.C working principle

The first step (Fuzzification) consists of transforming the numeric values on linguistic values that will be treated by the
Inference engine (the second phase of FLC) which contains different inference rules, based on predefined fuzzy methods and experimental knowledge, to define a logical connection between the input and output variables by applying. After that, the computed fuzzy value is treated by the last part of the FLC, Defuzzification phase, in order to determine the final numeric value of the output solution.

In our work, we have chosen to use the Mamdani method for the Inference engine step which consists of applying MaxMin relation between the membership degrees of the treated values as explained in [22] and the Gravity Center method, as given in [23], for the defuzzification phase that converts the fuzzy value into numeric value by applying (18).

Value $_{\text {output }}=\frac{\int_{i} \mu_{i} \cdot V F_{i}}{\int_{i} \mu_{i}}$

where:

- $\mu_{i}$ is the membership degree of the fuzzy value.

- $V F_{i}$ is the fuzzy value.

- Value $e_{\text {output }}$ is the computed output numeric value.

\section{B. Improvements applied on speed control system}

In this part, we present the different blocks we developed for our controller-

For the Fuzzification phase, based on the work presented in [24], we have divided the first input variable "E", which is the error between the speed reference and the measured one as given in (19), in seven fuzzy variables as shown in Figure 10. The second input variable "dE", which is the variation of the error given by (20), in three fuzzy variables as shown in figure 11. Finally, the output variable "Tem*",which is the computed torque reference, in seven fuzzy variables as shown in figure 12. Different figures show that we used a number of mixed trapezoid and triangle sets.

Finally, the different rules defined for the inference engine are presented in Table 4.

$$
\begin{gathered}
E(k)=\Omega^{*}-\Omega \\
d E=E(k)-E(k-1)
\end{gathered}
$$

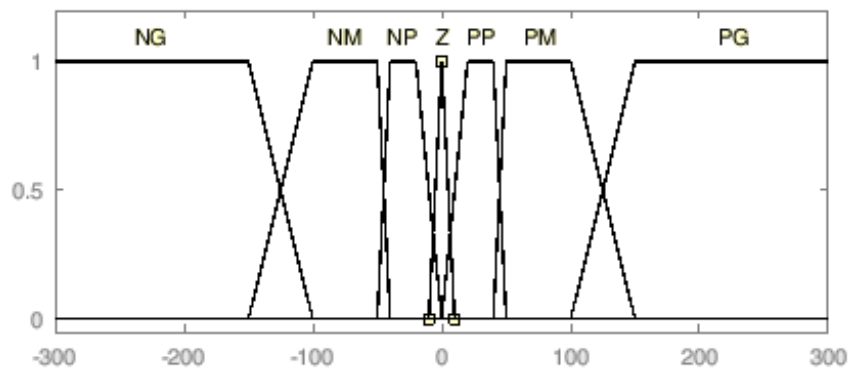

Fig. 10. Membership Functions of the input $\mathrm{E}$ 


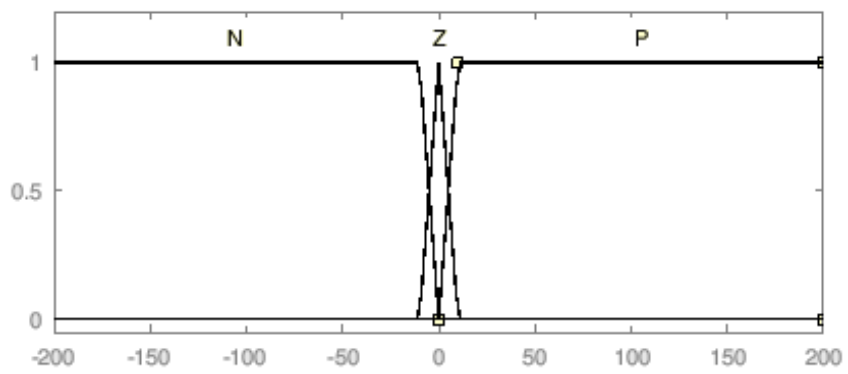

Fig. 11. Membership Functions of the input dE

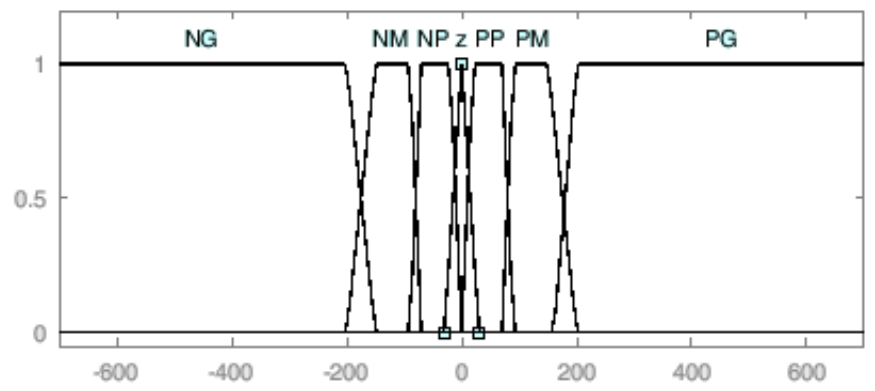

Fig. 12. Membership Functions of the output Tem*

TABLE IV. INFERENCE RULES OF FL SPEED CONTROLLER

\begin{tabular}{|l|l|l|l|}
\hline E dE & N & Z & P \\
\hline NG & NG & NG & NG \\
\hline NM & NG & NM & NG \\
\hline NP & NM & NP & NM \\
\hline Z & NP & Z & PP \\
\hline PP & PM & PP & PM \\
\hline PM & PG & PM & PG \\
\hline PG & PG & PG & PG \\
\hline
\end{tabular}

C. Developed Fuzzy-MPPT system

\section{1) The DC-DC converter}

As explained in [25], a boost converter is chosen based on its characteristics allowing the required $340 \mathrm{~V}$ minimum as DC input of the inverter to obtain the needed $240 \mathrm{~V}$ in its AC output and also allowing an almost permanent tracking of the desired MPP.

Figure 13 presents the equivalent electrical circuit of the BOOST DC-DC converter that we have adopted for our work.

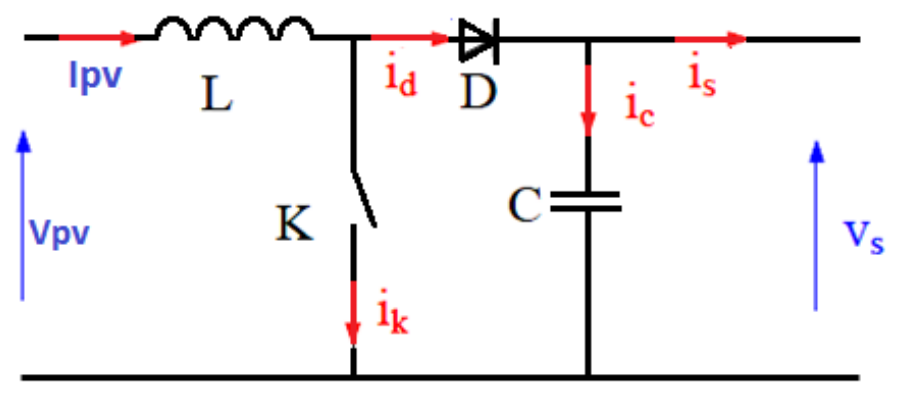

Fig. 13. General structure of BOOST converter

Using the BOOST Converter classical structure, we have modeled our converter based on the model given by (21) and (22).

$$
\begin{aligned}
& I_{S}=(1-\alpha) I_{P V} \\
& V_{S}= \frac{V_{P V}}{(1-\alpha)} \\
& \text { 2) } F L-M P P T \text { Control algorithm }
\end{aligned}
$$

We fixed two input variables basing on the work given in [26]. These two variables are E, given by (23), and $\mathrm{dE}$, given by (24).

$$
\begin{aligned}
& E(k)=\frac{P p v(k)-P p v(k-1)}{V p v(k)-V p v(k-1)} \\
& d E=E(k)-E(k-1)
\end{aligned}
$$

For the fuzzification, we have divided the first input variable $\mathrm{E}$ in three fuzzy variables, the second input variable $\mathrm{dE}$ in two fuzzy variables and the output variable which is the computed duty cycle variable that we named $\mathrm{D}$, in seven fuzzy variables.

The different defined membership functions are given respectively by Figures 14, 15 and 16. As shown, we used a combination of trapezoid and triangle functions for these fuzzy sets. And finally, the different rules defined for the inference engine are presented in Table 4.

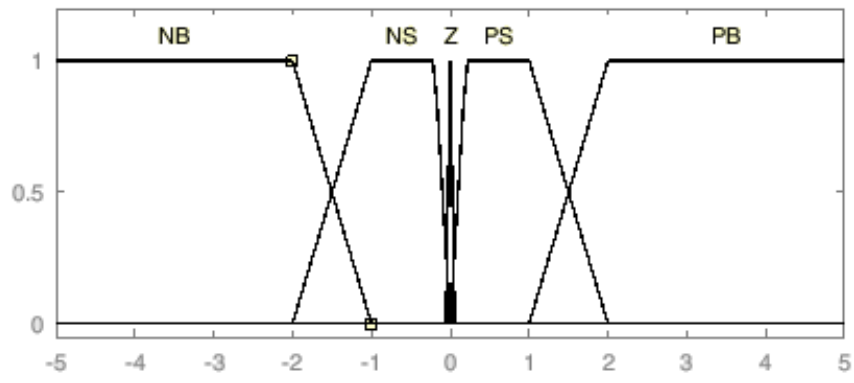

Fig. 14. Membership Functions of the input $\mathrm{E}$

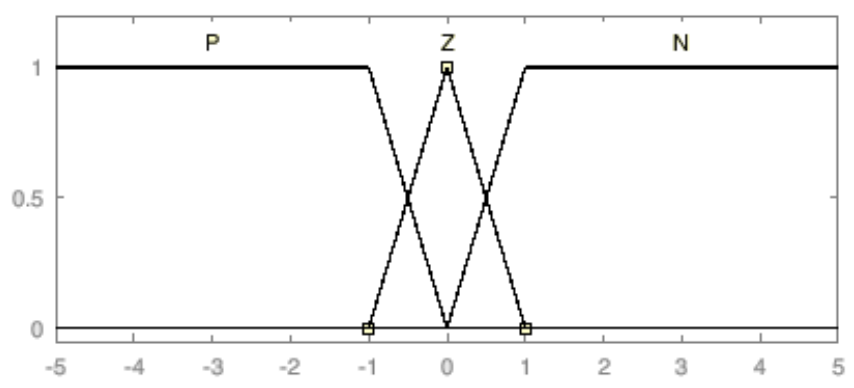

Fig. 15. Membership Functions of the input $\mathrm{dE}$

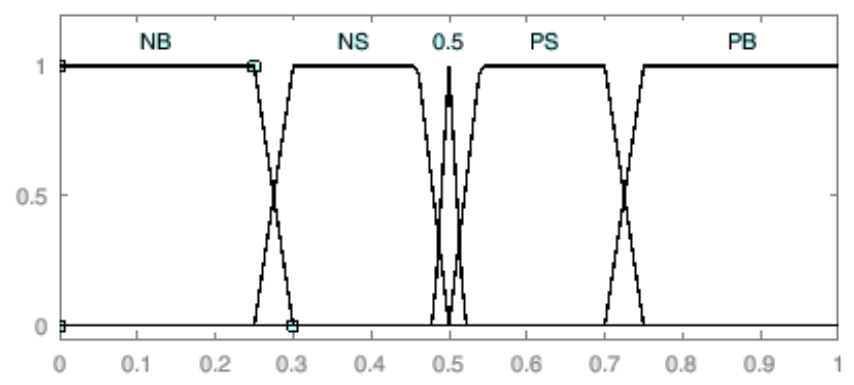

Fig. 16. Membership Functions of the output D 
Table 5 presents the nine defined rules for the inference engine. For this step, we conserved the Mamdani method for computing the output fuzzy value.

TABLE V. INFERENCE RULES FOR THE FL-MPPT CONTROLLER

\begin{tabular}{|l|l|l|l|}
\hline \multicolumn{1}{|c|}{ dEE } & P & Z & N \\
\hline NB & NB & NB & NB \\
\hline NS & NS & NS & NS \\
\hline Z & PB & 0.5 & NB \\
\hline PS & PS & PS & PS \\
\hline PB & PB & PB & PB \\
\hline
\end{tabular}

The gravity center method is used for the last operation, the Defuzzification step. And by applying this method on the obtained fuzzy value, the final output of the FLC, the duty cycle $\mathrm{D}$, is finally generated.

\section{RESULTS AND INTERPRETATION}

\section{A. Comparing Speed controllers}

In a first step, we tried to show the advantage of the added FLC in speed regulation of the system. For that, we simply used a DC voltage source, as previously shown in Figure 9, instead of the PVG and established different scenarios of simulation to compare our AMP performance with the originally preinstalled speed control and the developed one.

These different scenarios are testing in a first place the precision of the regulation process and the speed of response, taking account of both the climbing time and the reference establishing time. Then, we are comparing the robustness of the two regulators by introducing different disturbances on the AMP in the middle of its normal functioning.

The used model of the AMP and the PI speed regulator is given in Table 6.

TABLE VI. AMP AND PI CONTROLLER MODEL PARAMETERS

\begin{tabular}{|l|l|}
\hline Parameter & Value \\
\hline Resistance $\mathrm{R}_{\mathrm{s}}$ & $24.6 \Omega$ \\
\hline Resistance $\mathrm{R}_{\mathrm{r}}$ & $16.1 \Omega$ \\
\hline Inductance $\mathrm{L}_{\mathrm{m}}$ & $1.46 \mathrm{H}$ \\
\hline Inductance $\mathrm{L}_{\mathrm{s}}$ & $0.03 \mathrm{H}$ \\
\hline Inductance $\mathrm{L}_{\mathrm{r}}$ & $0.02 \mathrm{H}$ \\
\hline Pair of poles number & 2 \\
\hline Shaft inertia $\mathrm{J}$ & $6.510^{-3} \mathrm{Kg} \mathrm{m}^{2}$ \\
\hline Nominal power & $0.37 \mathrm{KW}$ \\
\hline Voltage & $220 \mathrm{~V}$ \\
\hline Frequency & $50 \mathrm{~Hz}$ \\
\hline Friction factor $\mathrm{F}$ & $1.7510^{-3} \mathrm{~N} . \mathrm{m} . \mathrm{s}$ \\
\hline Kp & 13 \\
\hline Ki & 1 \\
\hline Flux reference & $0.4 \mathrm{~Wb}$ \\
\hline
\end{tabular}

Figures 17,18 and 19 present the different measurements obtained by investigating different working cases given as next: $\mathrm{rad} / \mathrm{s})$.

- Figure 17: a constant speed reference is applied $(=100$

- Figure 18: a sudden variable speed reference is applied at $\mathrm{t}=3 \mathrm{~s}$ from $80 \mathrm{rad} / \mathrm{s}$ to $160 \mathrm{rad} / \mathrm{s}$.

- Figure 19: a constant speed reference is applied and a sudden variation in load torque is introduced at $\mathrm{t}=2.5 \mathrm{~s}$.
Each figure presents different curves where :

- Figures 17.a, 18.a and 19.a: Comparisons between the speed responses with both controllers.

- Figures 17.b, 18.b and 19.b: Comparisons between the variation of the pumped water flow rate.

- Figures 17.c, 18.c and 19.c: Show the generated control signal, which is the Torque reference, by the two controllers.

- Figures 17.d, 18.d and 19.d: show the difference between the measured stator currents with FL and PI controllers.

\section{B. Elaborated FL-MPPT controller}

In this part, we are showing the important improvements obtained by both the FL speed controller and the developed fuzzy logic MPPT control algorithm acting through the boost converter.

Table 7 shows the PVG and the boost converter models used in this study. Figure 20 shows the results in term of speed and flow when a constant speed reference $(=150 \mathrm{rad} / \mathrm{s})$ is applied while the irradiance and temperature are maintained constant (Irradiance $=1000 \mathrm{~W} / \mathrm{m}^{2}$ and Temperature $=25^{\circ} \mathrm{C}$ ). Figure 21 shows the variation of speed and flow while introducing sudden variations in irradiance values:

- At $\mathrm{t}=5 \mathrm{~s}$ : sudden variation of irradiance from $1000 \mathrm{~W} / \mathrm{m}^{2}$ to $200 \mathrm{~W} / \mathrm{m}^{2}$.

- At $\mathrm{t}=10 \mathrm{~s}$ : sudden variation of irradiance from $200 \mathrm{~W} / \mathrm{m}^{2}$ to $800 \mathrm{~W} / \mathrm{m}^{2}$.

TABLE VII. PVG AND BoOST MODEL PARAMETERS

\begin{tabular}{|l|l|}
\hline GPV Parameters & Values \\
\hline Parallel Strings & 1 \\
\hline Series-connected Strings & 5 \\
\hline Series Resistance $\mathrm{R}_{\mathrm{s}}$ & $24.6 \Omega$ \\
\hline Shunt Resistance $\mathrm{R}_{\mathrm{sh}}$ & $16.1 \Omega$ \\
\hline Light-Generated Current $\mathrm{I}_{\mathrm{L}}$ & $1.265 \mathrm{~A}$ \\
\hline Diode Ideality Factor & 2.19 \\
\hline Diode Saturation Current $\mathrm{I}_{\mathrm{D}}$ & $2.25^{*} 10^{-12} \mathrm{~A}$ \\
\hline Boost Parameters & Values \\
\hline Inductance L & $0.65^{*} 10^{-3} \mathrm{H}$ \\
\hline Capacitance C & $100^{*} 10^{-5} \mathrm{~F}$ \\
\hline Diode : Ron, Lon, Vf & $0.01 \Omega, 0 \mathrm{H}, 0.8 \mathrm{~V}$ \\
\hline
\end{tabular}

\section{Results Discussion}

Figures 17, 18 and 19 shows that both controllers pursue perfectly the reference and present a short climbing time (= $0.2 \mathrm{~s})$. Meanwhile, the PI controller shows a $10 \%$ overshooting while the FL controller shows almost $0 \%$ overshooting. In term of robustness, FL controller better reaction towards different disturbances applied on the system while PI controller shows longer time in stabilizing the system after load torque and reference sudden variations.

Figure 20 shows that, without an MPPT regulation system, the speed and consecutively the flow of the AMP are unable to reach the proposed reference and the optimal working performances of the AMP even after more than 5 seconds. By introducing the FL-MPPT controller, the AMP was able to reach the asked working performance in less than 2 seconds. This proves that the performances of the PvPS are enhanced thanks to the additional controller which is also noticed in 
Figure 21 that shows the results acquired when using an FLMPPT regulator are much better than the acquired results

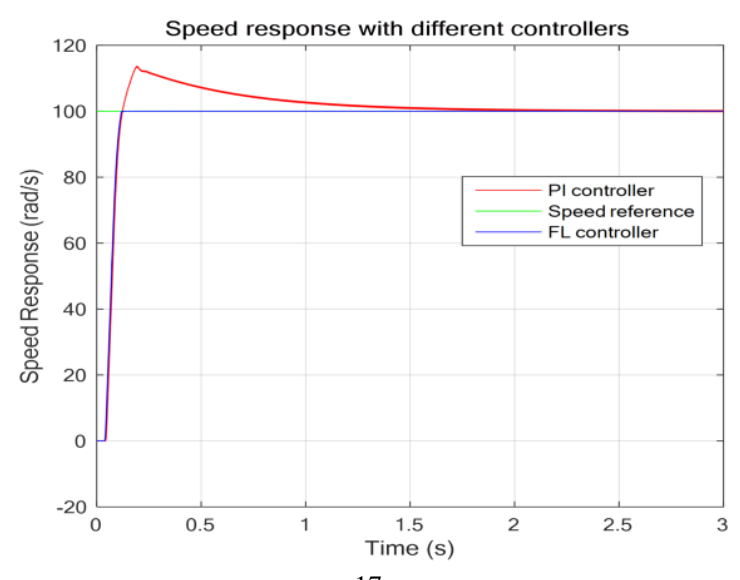

17.a

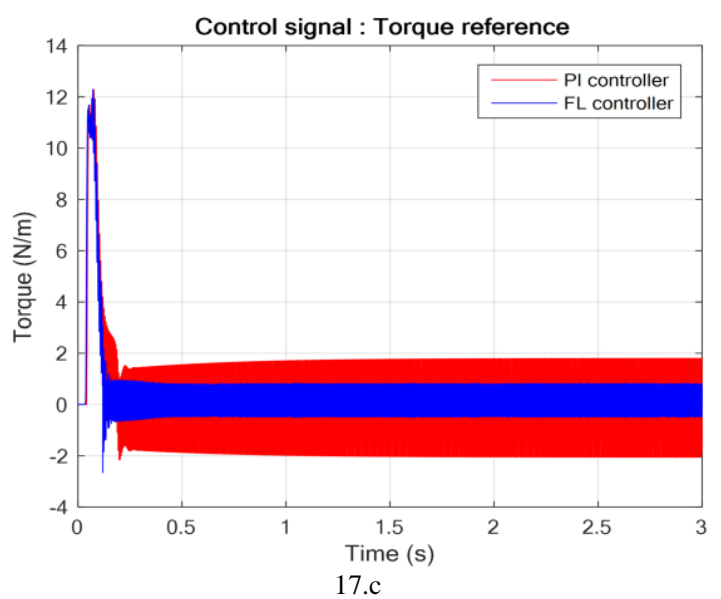

without it especially in facing the sudden variation of available sun irradiance.
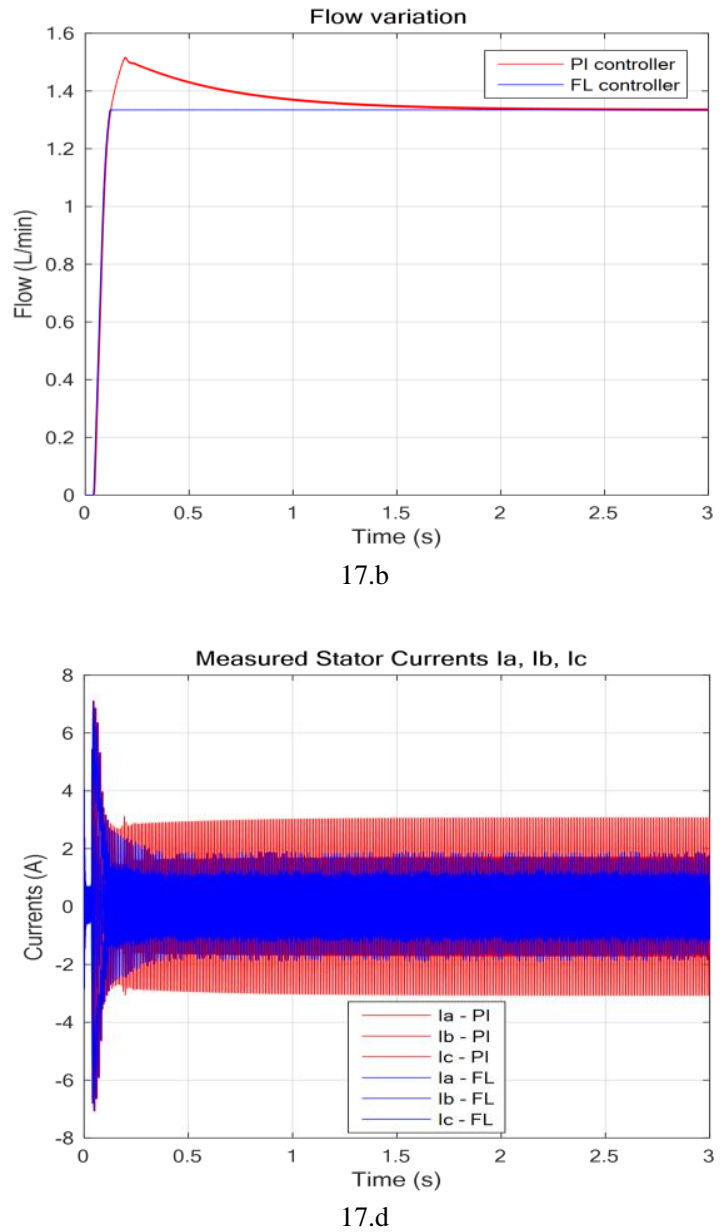

Fig. 17. Different measurements with constant speed reference 


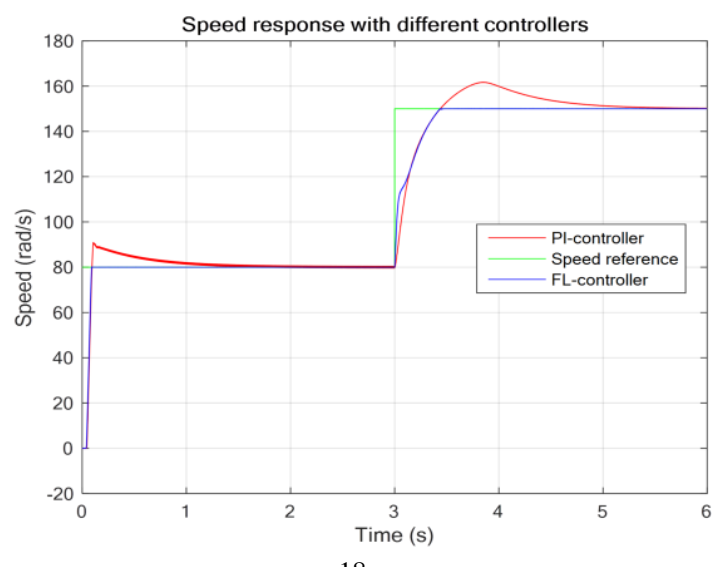

18.a

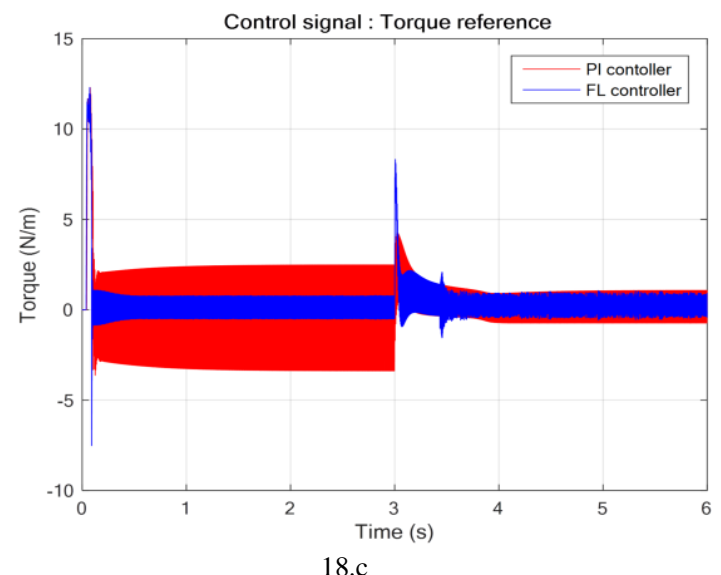

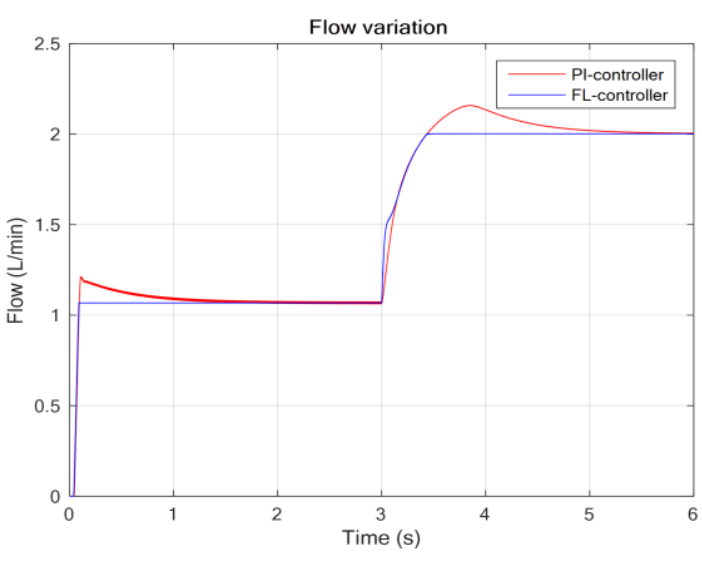

18.b

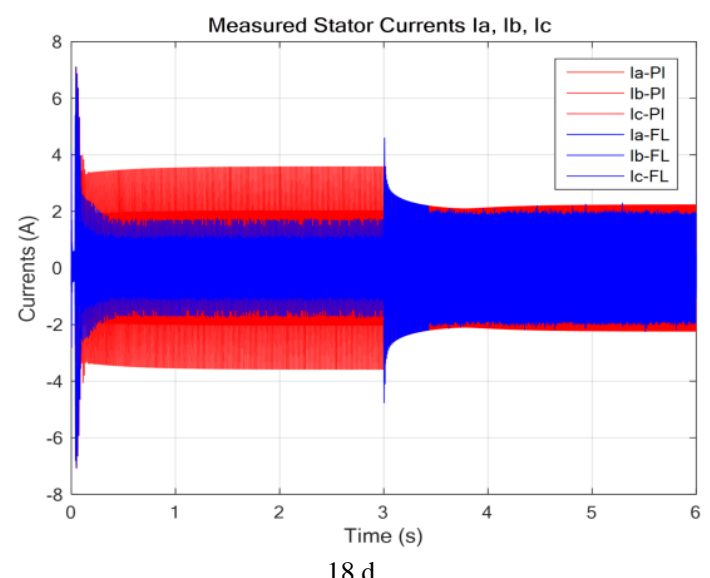

18.d

Fig. 18. Different measurements with variable speed reference
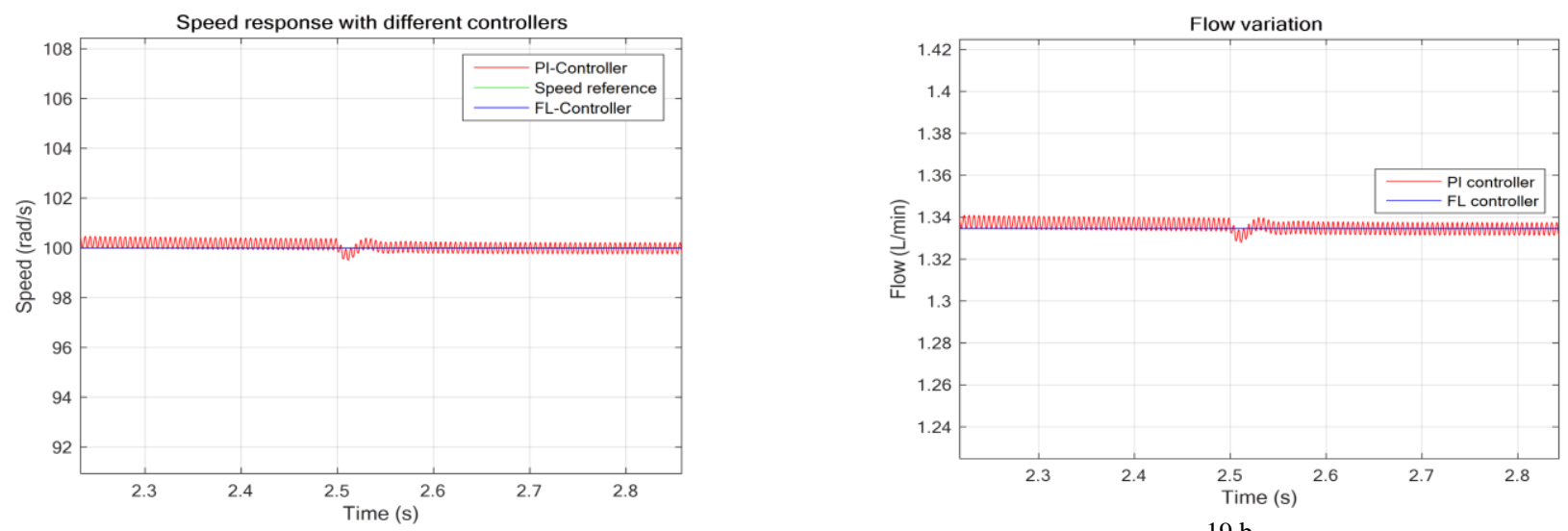

19.a

19.b 

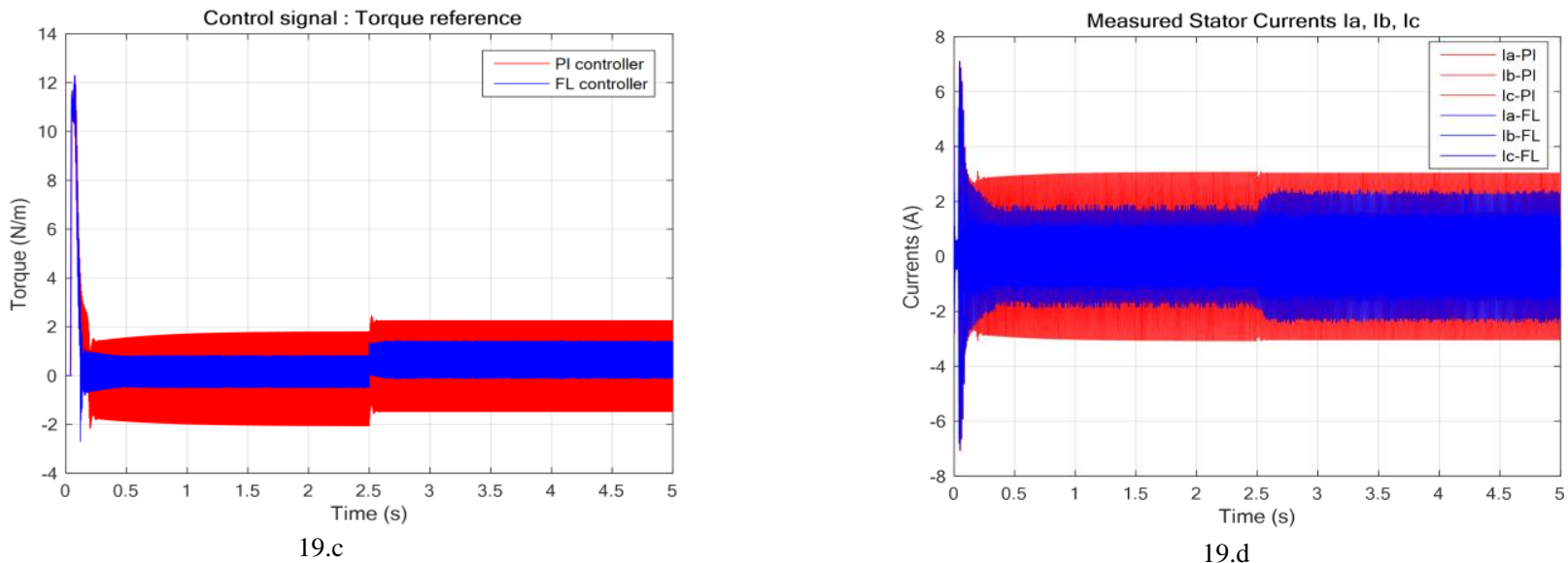

Fig. 19. Different measurements with variable load torque
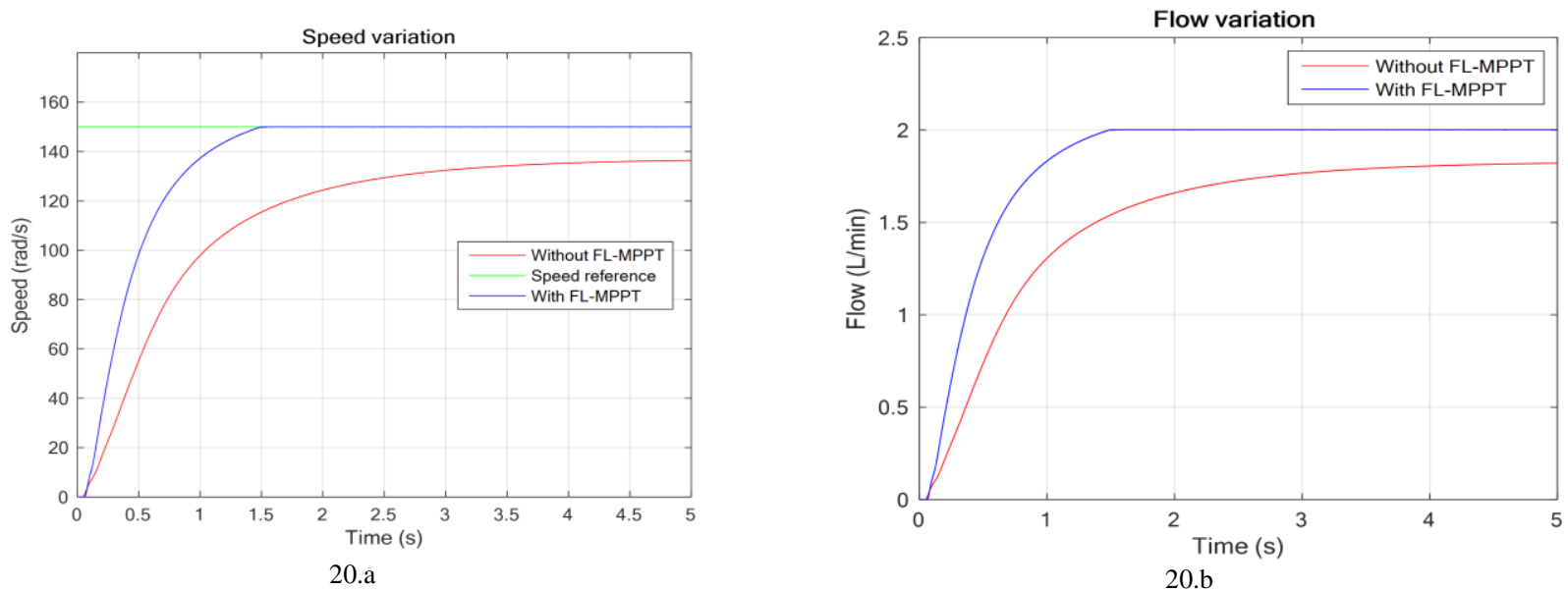

Fig. 20. Comparing Speed and Flow measurements for a stable solar irradiation
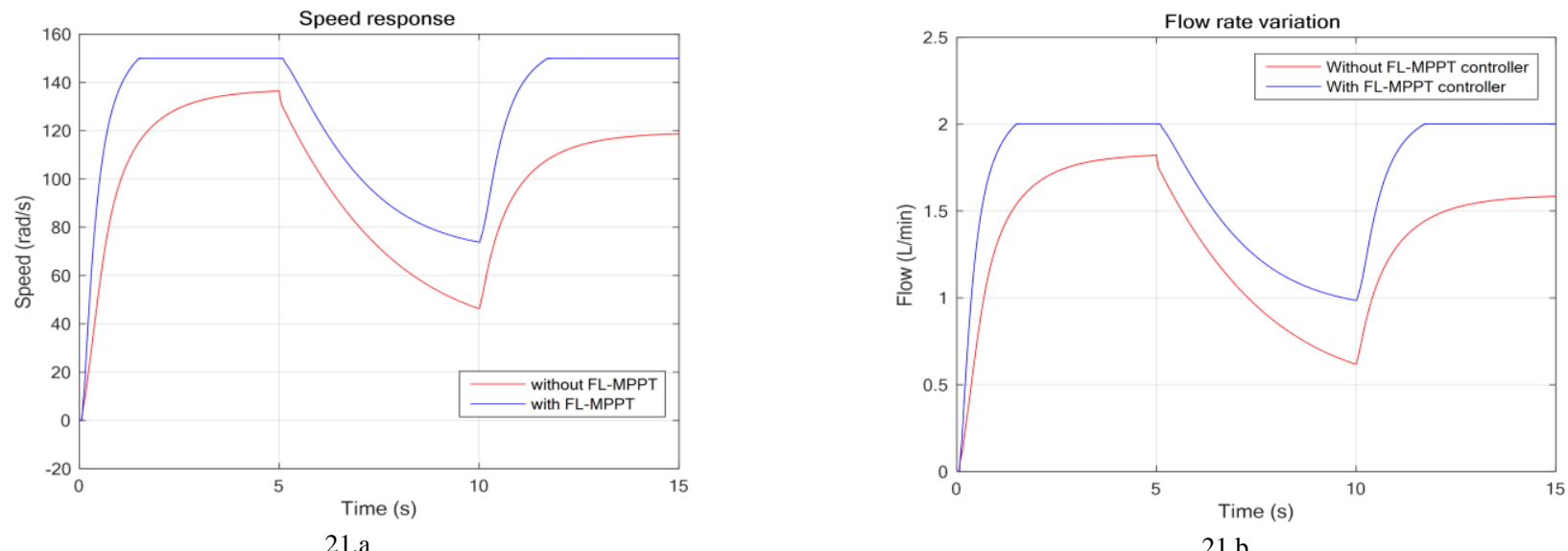

Fig. 21. Speed and Flow measurements for sudden variations in solar irradiation

\section{CONCLUSION}

The different results obtained by simulating the developed speed control system in a first place showed the important advantages of using an FL controller instead of a conventional
PI controller in term of time of response, stability and robustness against different disturbances. In a second place, the implementation of a DC-DC converter controlled by an MPPT algorithm based on FL technique shows an upgraded 
performance of the PV Pumping system in different scenarios of solar irradiance variations.

This work will be followed by practical investigation by implementing the different algorithms on embedded boards such us FPGAs, STM32s and ARDUINOs.

\section{REFERENCES}

[1] E. Román, R. Alonso, P. Ibañez, S. Elorduizapatarietxe, D. Goitia. "Intelligent PV Module for Grid-Connected PV Systems", IEEE Transactions on Industrial Electronics, Vol. 53, Issue 04, pp. 1066-1073, August 2006. [Online] Available: http://doi.org/10.1109/TIE.2006.878327

[2] N. A. Ahmed, A. K. Al-Othman, M. R. Al Rashidi, "Development Of An Efficient Utility Interactive Combined Wind/Photovoltaic/Fuel Cell Power System With MPPT And DC Bus Voltage Regulation", Electric Power Systems Research, Vol. 81, Issue 05, pp. 1096-1106, May 2011. [Online] Available: http://dx.doi.org/10.1016/j.epsr.2010.12.015

[3] V. Vongmanee, "The Photovoltaic Pumping System Using A Variable Speed Single Phase Induction Motor Drive Controlled By Field Oriented Principle", The 2004 IEEE Asia-Pacific Conference on Circuits and Systems, December 6-9, 2004.

[4] A. A. Ghoneim, "Design optimization of photovoltaic powered water pumping systems", Energy Conversion and Management, Vol. 47, Issues $11-12$, pp. 1449-1463, July 2006. [Online] Available: http://dx.doi.org/10.1016/j.enconman.2005.08.015

[5] Y. Bakelli, A. H. Arab, B. Azoui, "Optimal sizing of photovoltaic pumping system with water tank storage using LPSP concept", Solar Energy, Vol. 85, Issue 02, pp.288-294, February 2011. [Online] Available: $\quad$ http://dx.doi.org/10.1016/j.solener.2010.11.023

[6] R. Faranda, S. Leva, "Energy Comparison of MPPT Techniques for PV Systems", WSEAS Transactions on Power Systems, Vol. 3, Issue 06, pp. 446-455, June 2008.

[7] A. Terki , A. Moussi, A. Betka, N. Terki, "An Improved Efficiency Of Fuzzy Logic Control Of PMBLDC For PV Pumping System", Applied Mathematical Modelling, Vol. 36, Issue 02, pp. 934-944, March 2012. [Online] Available: http://dx.doi.org/10.1016/j.apm.2011.07.042

[8] G. J. Yu , Y. S. Jung, J. Y. Choi , G. S. Kim, "A Novel Two-Mode MPPT Control Algorithm Based On Comparative Study Of Existing Algorithms", Solar Energy, Vol. 76, Issue 04, pp. 455-463, April 2004. [Online] Available: http://dx.doi.org/10.1016/j.solener.2003.08.038

[9] E. Ģam , İ. Kocaarslan, "Load Frequency Control In Two Area Power Systems Using Fuzzy Logic Controller", Energy Conversion and Management, Vol. 46, Issue 02, pp. 233-243, January 2005. [Online] Available: http://dx.doi.org/10.1016/j.enconman.2004.02.022

[10] S. P. Binguac, "On The Compatibility Of Adaptive Controllers (Published Conference Proceedings style)," in Proc. 4th Annu. Allerton Conf. Circuits and Systems Theory, New York, 1994, pp. 8-16.

[11] D. Mezghani, H. Othmani, F. Sassi, A. Mami, G. Dauphin-Tanguy, "A New Optimum Frequency Controller of Hybrid Pumping System: Bond Graph Modeling-Simulation and Practice with ARDUINO Board", International Journal of Advanced Computer Science and Applications, Vol. 8, Issue 01, pp. 78-87, 2017. [Online] Available: http://dx.doi.org/10.14569/IJACSA.2017.080112

[12] H. Chaouali, H. Othmani, D. Mezghani, H. Jouini, A. Mami, "Fuzzy logic control scheme for a 3 phased asynchronous machine fed by Kaneka GSA-60 PV panels", 7th International IEEE Renewable Energy Congress (IREC), Tunisia 2016, DOI: https://doi.org/10.1109/IREC.2016.7478893

[13] H. Othmani, F. Sassi, D. Mezghani, A. Mami, "Comparative Study between Fuzzy Logic Control and Sliding Mode Control for Optimizing the Speed Deportment of a Three Phase Induction Motor", International Review of Automatic Control, Vol. 9, Issue 03, pp. 175-181, May 2016. [Online] Available: https://doi.org/10.15866/ireaco.v9i3.9269
[14] D. Mezghanni, R. Andoulsi, A. Mami, G. Dauphin -Tanguy, "Bond Graph Modeling Of A Photovoltaic System Feeding An Induction Motor-Pump", Simulation Modelling Practice and Theory, Vol. 15, Issue 10, pp. 1224-1238, November 2007. [Online] Available: http://dx.doi.org/10.1016/j.simpat.2007.08.003

[15] D. Kairous, B. Belmadani, "Robust Fuzzy-Second Order Sliding Mode based Direct Power Control for Voltage Source Converter", International Journal of Advanced Computer Science and Applications, Vol. 6, Issue 08, pp. 167-175, 2015. [Online] Available: http://dx.doi.org/10.14569/IJACSA.2015.060823

[16] I. Birou, V. Maier, S: Pavel, C. Rusu, "Indirect Vector Control of an Induction Motor with Fuzzy-Logic based Speed Controller", Advances in Electrical and Computer Engineering, Vol. 10, Issue 01, pp. 116-120, February 2010. [Online] Available: https://doi.org/10.4316/AECE.2010.01021

[17] D. Mezghani, M. A. Jaballah, A. Mami, " A new design vector control of pumping photovoltaic system: Tests and measurements", Europeen journal of scientific reseach, vol 61, Issue 04, pp. 493-507, October 2011.

[18] D. Mezghani, A. Mami, " Input-Output Linearizing Control Of Pumping Photovoltaic System: Tests And Measurements By Micro-Controller Stm32", International journal of advances in engineering and thechnology, vol 4, Issue 02, pp. 25-37, September 2012. [Online] Available: http://doi.org/10.7323/ijaet/V4_iss2

[19] N. A. Gounden, S. A. Peter, H. Nallandula, S. Krithiga, "Fuzzy logic controller with MPPT using line-commutated inverter for three-phase grid-connected photovoltaic systems", Renewable Energy, Vol. 34, Issue 03, pp. 909-915, March 2009. [Online] Available: http://dx.doi.org/10.1016/j.renene.2008.05.039

[20] H. Iqbal, M. Babar, "An Approach for Analyzing ISO/IEC 25010 Product Quality Requirements based on Fuzzy Logic and Likert Scale for Decision Support Systems", International Journal of Advanced Computer Science and Applications, Vol. 7, Issue 12, pp. 245-260, 2016. [Online] Available: http://dx.doi.org/10.14569/IJACSA.2016.071232

[21] A. Varghese, J. P. Sreedhar, S. Kolamban, S. Nayaki, "Outcome based Assessment using Fuzzy Logic", International Journal of Advanced Computer Science and Applications, Vol. 8, Issue 01, pp. 103-106, 2017. [Online]

Available: http://dx.doi.org/10.14569/IJACSA.2017.080115

[22] F. Culić, D. Matić, B. Dumnić, V. Vasić, "Optimal Fuzzy Controller Tuned by TV-PSO for Induction Motor Speed Control", Advances in Electrical and Computer Engineering, Vol. 11, Issue 01, pp. 49-54, February 2011. [Online] Available: http://doi.org/10.4316/AECE.2011.01008

[23] K. Laaroussi, M. Zelmat, M. Rouff, "Implementation of a Fuzzy Logic System to Tune a PI Controller Applied to an Induction Motor", Advances in Electrical and Computer Engineering, Vol 9, Issue 03, pp. 107-113, October 2009. [Online] Available: http://doi.org/10.4316/AECE.2009.03019

[24] M. Tuna, C. B. Fidan, S. Kocabey, S. Görgülü, "Effective and Reliable Speed Control of Permanent Magnet DC (PMDC) Motor under Variable Loads", Journal of Electrical Engineering and Technology (JEET), Vol. 10, Issue 05, pp. 2170-2178, September 2015. [Online] Available: http://dx.doi.org/10.5370/JEET.2015.10.5.2170

[25] Geoffrey R. Walker and Paul C. Sernia, "Cascaded DC-DC Converter Connection of Photovoltaic Modules", IEEE Transactions on Power Electronics, VOL. 19, Issue 04, pp. 1130-1139, July 2004. [Online] Available: http://doi.org/10.1109/TPEL.2004.830090

[26] Ahmad Al Nabulsi and Rached Dhaouadi , "Efficiency Optimization of a DSP-Based Standalone PV System Using Fuzzy Logic and Dual-MPPT Control", IEEE Transactions On Industrial Informatics, VOL. 8, Issue 03, August 2012. [Online] Available: http://doi.org/10.1109/TII.2012.2192282 